\title{
STUDIES OF THE PULMONARY CIRCULATION. I. THE CIRCULA- TION TIME FROM THE PULMONARY ARTERY TO THE FEMORAL ARTERY AND THE QUANTITY OF BLOOD IN THE LUNGS IN NORMAL INDIVIDUALS ${ }^{1,2}$
}

\author{
BY RICHARD V. EBERT, CRAIG W. BORDEN, HERBERT S. WELLS, \\ AND RUSSELL H. WILSON
}

\begin{abstract}
(From the Department of Medicine, University of Minnesota, and the Veterans Administration Hospital, Minneapolis, Minn.)
\end{abstract}

(Received for publication February 21, 1949)

The measurement of the volume of blood contained within the vessels of the lungs has excited considerable interest for many years. A direct method of measurement by clamping the pulmonary vessels, removing the lungs and determining the amount of hemoglobin contained therein has been used on laboratory animals (1). A method that is applicable to intact animals and to human beings was developed by Stewart (2), using the formula $Q=\frac{T V}{60}$, where $V$ represents the minute volume of the heart, $Q$ the volume of the blood in the lungs and $T$ the mean pulmonary circulation time in seconds. By measuring $V$ and $T$, Stewart found that the average pulmonary blood volume $(Q)$ in a group of dogs amounted to 16 per cent of the total blood volume.

Blumbart and Weiss (3) determined the pulmonary circulation time in normal human subjects using an active deposit of radium. The material was injected into an antecubital vein of one arm and the time of arrival in the right heart and the brachial artery was noted. The term "crude pulmonary circulation time" was used to refer to the difference between the time of arrival of the radium in the right heart on the one hand, and the time of its arrival in the brachial artery on the other. From the "crude pulmonary circulation time" and the cardiac output the pulmonary blood volume was estimated.

The assumption was made both by Stewart (2)

1 Published with permission of the Chief Medical Director, Veterans Administration, who assumes no responsibility for the opinions expressed or conclusions drawn by the authors.

2 Presented in part at a meeting of The American Society for Clinical Investigation in Atlantic City, N. J., May 3, 1948. and by Blumgart and Weiss (4) that the most rapid circulation time does not differ significantly from the mean circulation time. Hamilton, Moore, Kinsman, and Spurling (5) measured the dye concentration in serial samples of blood obtained from the femoral artery immediately after the injection of a dye into a peripheral vein. When the concentration of dye in each sample was plotted against the time of collection of the sample, a characteristic curve was obtained which demonstrated that the mean circulation time differs considerably from the most rapid circulation time. By studies on artificial models they also validated Stewart's method for determining pulmonary blood volume. In addition, they developed a method of estimating the cardiac output from the concentration curve of the dye. By determining the mean circulation time (from a peripheral vein to the femoral artery) and the cardiac output, the volume of blood between the points of introduction and removal of dye was calculated from Stewart's formula.

The rate of peripheral venous flow is variable (3) and introduces considerable inaccuracy in the estimation of pulmonary blood volume by the method of Hamilton et al. (5). The direct injection of dye into the pulmonary artery through a catheter obviates this difficulty by eliminating the circulation time from the peripheral vein to the pulmonary artery. Catheterization of the pulmonary artery also permits accurate determination of the cardiac output $(6,7)$.

\section{METHOD}

Thirteen normal fasting male adults between the ages of 30 and 40 were studied. One was eliminated from the series because of the development of marked anxiety during the procedure resulting in an extremely high car- 
diac output. The subjects were either physicians or laboratory workers. A No. $8 \mathrm{~F}$ or No. 9F catheter was introduced into the pulmonary artery by the method of Cournand, and a No. 18 needle with stylet was inserted into the femoral artery (8). The oxygen consumption was measured with a closed circuit spirometer and samples were drawn from the pulmonary artery and femoral artery for the determination of oxygen content by the method of Van Slyke and Neill (9). Immediately thereafter, $5 \mathrm{cc}$. of a solution of the dye T-1824 containing 300 $\mathrm{mg}$. of dye per $100 \mathrm{cc}$. were introduced as rapidly as possible through the catheter into the pulmonary artery, the average time required for the injection of the dye being 0.8 seconds. Time intervals were recorded on a direct writing electric kymograph by an assistant. In order to permit more accurate timing of the initial appearance of the dye in the circulation, $1 \mathrm{cc}$. of the dye was introduced into the catheter before beginning the injection. $^{3}$ Consecutive samples of blood were collected.

For the determination of the dye curve, the serum was separated and $0.1 \mathrm{cc}$. was diluted with $2 \mathrm{cc}$. of saline solution. The dye concentration was then determined in the Evelyn photoelectric micro-colorimeter using a con-

3 The No. $9 \mathrm{~F}$ catheter contains a volume of about $1.8 \mathrm{cc}$. from the femoral artery in small glass tubes which were arranged in series in a wooden rack. The blood spurting from the needle was allowed to flow directly into the sampling tubes. The average time required for collection of a sample was 1.9 seconds, each tube receiving 0.3 to $0.5 \mathrm{cc}$. of blood. After completion of the sampling fiom the femoral artery, the dye remaining in the catheter was washed into the circulation and a sample of blood was taken 10 minutes later. The plasma volume was determined from the concentration of dye in the plasma (10), and the total blood volume from the plasma volume and hematocrit reading. trol sample of serum similarly diluted with saline as a blank.

To determine the mean circulation time, the concentration of dye in each sample was plotted against the time of collection of the sample on linear graph paper. The time of each sample was determined by measuring the interval between the mean time of the injection of the dye and the mean time of the collection of the sample. After the curve was plotted, the area subtended by the primary dye curve was measured with a planimeter. The vertical line that divides this area into two equal parts represents the mean circulation time.

The cardiac output was calculated by the Fick principle (6). The quantity of blood contained in the pulmonary vessels, left heart, aorta and certain larger arteries $(Q)$ is equal to the

$\frac{\text { cardiac output (cc./min.) } \times \text { mean circulation time (sec.) }}{60}$ according to the formula of Stewart (2).

\section{RESULTS}

The results are given in Table $I$, and a typical dye curve is illustrated in Figure 1. In all the experiments, the concentration of the dye in the blood obtained from the femoral artery was at or near zero before recirculation began. In those cases in which recirculation began before the primary curve was completed, the curve was extended to the base line for purposes of calculation (Figure 2). The average circulation time in the 12 subjects was 10.2 seconds with a standard deviation of \pm 1.6 , and the average duration of the primary curve was $12.3 \pm 2.4$ seconds.

TABLE I

\begin{tabular}{|c|c|c|c|c|c|c|c|c|c|}
\hline Subject & $\begin{array}{c}\text { Surface } \\
\text { area }\end{array}$ & $\begin{array}{c}\text { Oxygen } \\
\text { consumed }\end{array}$ & $\begin{array}{c}\text { Arterio- } \\
\text { venous } \\
\text { oxygen } \\
\text { difference }\end{array}$ & $\begin{array}{l}\text { Cardiac } \\
\text { output }\end{array}$ & $\begin{array}{c}\text { Cardiac } \\
\text { index }\end{array}$ & $\begin{array}{c}\text { Mean } \\
\text { circulation } \\
\text { time }\end{array}$ & $\begin{array}{l}\text { Duration } \\
\text { of curve }\end{array}$ & $Q$ & $\begin{array}{c}\text { Total } \\
\text { blood } \\
\text { volume }\end{array}$ \\
\hline $\begin{array}{l}\text { B. G. } \\
\text { A. F. } \\
\text { J. W. } \\
\text { A. L. F. } \\
\text { D. N. } \\
\text { R. W. } \\
\text { D. B. } \\
\text { C. C. } \\
\text { F. W. } \\
\text { L. Z. } \\
\text { H. F. } \\
\text { G. P. } \\
\text { J. H.* } \\
\text { Mean }\end{array}$ & $\begin{array}{l}\text { sq. } m . \\
1.78 \\
1.79 \\
1.80 \\
1.83 \\
1.86 \\
1.89 \\
1.92 \\
1.93 \\
1.95 \\
2.07 \\
2.08 \\
2.14 \\
1.80 \\
1.92\end{array}$ & $\begin{array}{c}c c . / \min . \\
233 \\
193 \\
272 \\
239 \\
287 \\
215 \\
266 \\
235 \\
304 \\
311 \\
292 \\
282 \\
251 \\
261\end{array}$ & $\begin{array}{c}\text { vol. per cent } \\
4.01 \\
4.91 \\
3.58 \\
3.17 \\
3.80 \\
4.15 \\
3.25 \\
4.15 \\
3.37 \\
4.39 \\
3.63 \\
3.79 \\
2.58 \\
3.85\end{array}$ & $\begin{array}{c}\text { L./min. } \\
\mathbf{5 . 8 1} \\
3.93 \\
7.60 \\
7.54 \\
7.55 \\
5.18 \\
8.18 \\
5.66 \\
9.02 \\
7.08 \\
8.04 \\
7.44 \\
9.74 \\
6.92\end{array}$ & $\begin{array}{c}\text { L./min./sq. } m . \\
3.26 \\
2.19 \\
4.20 \\
4.12 \\
4.05 \\
2.74 \\
4.26 \\
2.94 \\
4.61 \\
3.42 \\
3.86 \\
3.48 \\
5.41 \\
3.59\end{array}$ & $\begin{aligned} \text { sec. } \\
10.5 \\
12.1 \\
11.8 \\
9.5 \\
7.7 \\
10.4 \\
12.1 \\
11.4 \\
7.6 \\
9.4 \\
9.2 \\
10.9 \\
7.6 \\
10.2\end{aligned}$ & \begin{tabular}{|r|} 
sec. \\
13.5 \\
12.8 \\
14.8 \\
11.2 \\
11.0 \\
15.0 \\
15.8 \\
11.0 \\
8.5 \\
11.0 \\
8.7 \\
14.0 \\
5.1
\end{tabular} & $\begin{array}{c}c c . \\
1010 \\
790 \\
1490 \\
1190 \\
970 \\
900 \\
1650 \\
1080 \\
1140 \\
1110 \\
1230 \\
1350 \\
1230 \\
1160\end{array}$ & $\begin{array}{l}c c . \\
5780 \\
5320 \\
5800 \\
5710 \\
5000 \\
5050 \\
5760 \\
6200 \\
5980 \\
6690 \\
6250 \\
7860 \\
6400 \\
5950\end{array}$ \\
\hline $\begin{array}{c}\text { Standard } \\
\text { deviation }\end{array}$ & \pm 0.38 & \pm 0.37 & \pm 0.50 & \pm 1.46 & \pm 0.72 & \pm 1.6 & \pm 2.4 & \pm 246 & \pm 776 \\
\hline
\end{tabular}

* Omitted in the calculation of mean values because the subject showed evidence of marked anxiety during the procedure. 


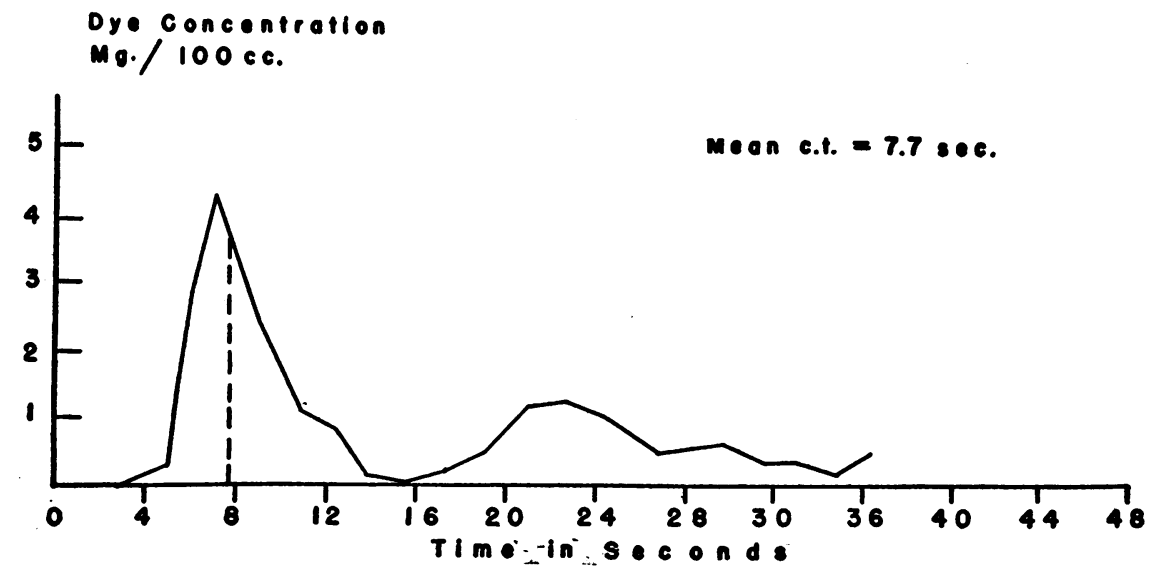

Fig. 1. Dye Concentration Curve in Normal Subject

The dye concentration reached zero before recirculation began. The mean circulation time is represented by the broken vertical line.

The cardiac output for the group was $6.92 \pm$ 1.5 , and the cardiac index was $3.59 \pm 0.72$ liters per minute. The mean value for $Q$, calculated from Stewart's formula, was $1160 \pm 246 \mathrm{cc}$. Correcting the individual values for $Q$ to 1.73 sq. $\mathrm{m}$. of body surface, gave a mean value for the group of $1045 \pm 200$ cc. Expressed as per cent of total blood volume, the mean for the group was 19.5 .

\section{DISCUSSION}

As emphasized by Hamilton (5), the mean circulation time differs from the most rapid circulation time. The primary dye curve from which the mean circulation time is calculated is produced by dye particles travelling from the pul- monary artery to the femoral artery at different rates of speed. In the study by Blumgart and Weiss (4), the most rapid circulation time rather than the mean circulation time was determined. If the apparatus for detecting the arrival of the radium in the brachial artery were extremely sensitive, the most rapid circulation time would differ considerably from the mean circulation time. If, however, the time recorded really represents the peak concentration of the substance, the value should correspond closely to the mean circulation time. As can be seen in Figure 1, the mean circulation time differs little from the time required to attain the maximum concentration of dye in the normal subject. It is of interest that the circula-

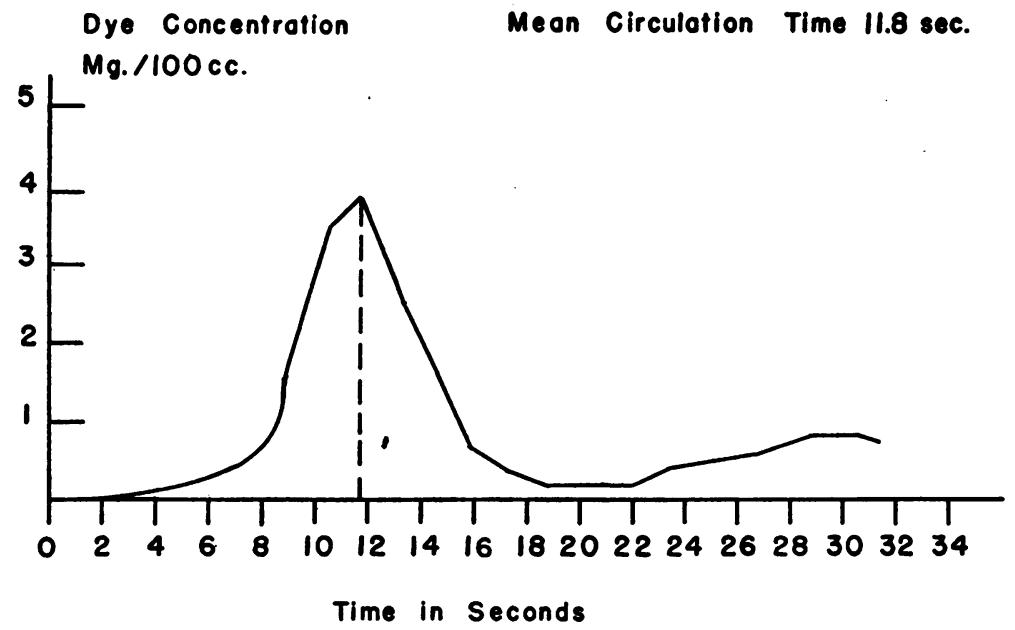

Fig. 2. Dye Concentration Curve in Normal Subject

The dye concentration did not reach zero before recirculation began. The mean circulation time is represented by the broken vertical line. 
tion time from the right auricle to the brachial artery, as measured by Blumgart and Weiss (3), is quite similar to the circulation time from the pulmonary artery to the femoral artery, as measured by the dye method, the average value for the former being 10.8 seconds and for the latter 10.2 seconds.

The value for $Q$, calculated from the formula of Stewart, represents the amount of blood contained within the pulmonary vessels, left heart, and certain of the larger arteries. Hamilton (5) has pointed out that on the systemic side of the circulation, $Q$ includes the blood in the aorta and iliac arteries together with all the blood contained within the other branches of the aorta to points where dye arrives no later than it does at the femoral artery. It is apparent that in the pulmonary vessels, $Q$ includes only blood which is circulating.

In comparing the value of $Q$ in the present study with that obtained by Hamilton, it should be pointed out that in his experiments, the dye was injected into an arm vein. Thus, the mean circulation time included the time required for the dye to travel from the arm to the pulmonary artery in addition to the time of passage from the pulmonary artery to the femoral artery. Blumgart and Weiss (3) found that the circulation time from the antecubital space of the arm to the right heart was 6.7 seconds. This fact explains the considerably higher value for $Q$ obtained by Hamilton and colleagues in normal subjects (5). The value for $Q$ in their studies was 2 liters as compared with 1.16 liters in the present experiment.

In order to determine the true pulmonary blood volume, it is necessary to know the mean circulation time from the pulmonary artery to the left auricle, a value which was not determined in the present experiments. From the studies available in the literature it is difficult to estimate the true pulmonary circulation time. Nevertheless, it is apparent that the true pulmonary blood volume is less than the value for $Q$. A more accurate estimation of the true pulmonary blood volume must await a method for determining the mean circulation time from the pulmonary artery to the left auricle.

\section{SUMMARY}

1. The mean circulation time from the pulmonary artery to the femoral artery was determined by injecting the dye $\mathrm{T}-1824$ into the pulmonary artery and measuring the concentration of the dye in consecutive samples of blood obtained from the femoral artery. The mean circulation time in 12 normal subjects was $10.2 \pm 1.6$ seconds.

2. The volume of blood contained in the pulmonary vessels, left heart, aorta, and certain of the larger systemic arteries was calculated from Stewart's formula using the mean circulation time and the cardiac output as measured by the direct Fick method. The mean volume for the group of 12 normal subjects was $1160 \pm 246 \mathrm{cc}$., or 19.5 per cent of the total blood volume.

\section{BIBLIOGRAPHY}

1. Plumier, L., La circulation pulmonaire chez le chien. Arch. internat. de physiol., 1904, 1, 176.

2. Stewart, G. N., The pulmonary circulation time, the quantity of blood in the lungs and the output of the heart. Am. J. Physiol., 1921, 58, 20.

3. Blumgart, H. L., and Weiss, S., Studies on the velocity of blood flow. VII. The pulmonary circulation time in normal resting individuals. J. Clin. Invest., 1927, 4, 399.

4. Blumgart, H. L., and Weiss, S., Studies on the velocity of blood flow. V. The physiological and pathological significance of the velocity of blood flow. J. Clin. Invest., 1927, 4, 199.

5. Hamilton, W. F., Moore, J. W., Kinsman, J. M., and Spurling, R. G., Studies on the circulation. IV. Further analyses of the injection method, and of changes in the hemodynamics under physiological and pathological conditions. Am. J. Physiol., 1932, 99, 534.

6. Fick, A., Ueber die Messung des Blutquantums in den Herzventrikeln. Verhandl. d. physical. med. gesselsch. z. Wurzburg, 1870, 2, 16.

7. Dexter, L., Haynes, F. W., Burwell, C. S., Eppinger, E. C., Sagerson, R. P., and Evans, J. M., Studies of congenital heart disease. II. The pressure and oxygen content of blood in the right auricle, right ventricle, and pulmonary artery in control patients, with observations on oxygen saturation and source of pulmonary "capillary" blood. J. Clin. Invest., 1947, 26, 554.

8. Cournand, A., Riley, R. L., Breed, E. S., Baldwin, E. deF., and Richards, D. W., Jr., Measurement of cardiac output in man using the technique of catheterization of the right auricle or ventricle. J. Clin. Invest., 1945, 24, 106.

9. Van Slyke, D. D., and Neill, J. M., The determination of gases in blood and other solutions by vacuum extraction and manometric measurement. $\mathrm{J}$. Biol. Chem., 1924, 61, 523.

10. Gibson, J. G., 2nd, and Evelyn, K. A., Clinical studies of blood volume; adaptation of method to photoelectric microcolorimeter. J. Clin. Invest., 1938, $17,153$. 